Brazilian Journal
of Chemical
Engineering

ISSN 0104-6632

Printed in Brazil

www.abeq.org.br/bjche

Vol. 29, No. 01, pp. 147 - 158, January - March, 2012

\title{
INVESTIGATION INTO THE ROLE OF NaOH AND CALCIUM IONS IN THE SYNTHESIS OF CALCIUM PHOSPHATE NANOSHELLS
}

\author{
C. H. Yeo ${ }^{1}$, S. H. S. Zein ${ }^{1 *}$, A. L. Ahmad ${ }^{1}$ and D. S. McPhail ${ }^{2}$ \\ ${ }^{1}$ School of Chemical Engineering, Engineering Campus, Universiti Sains Malaysia, \\ Seri Ampangan 14300 Nibong Tebal, Seberang Perai Selatan, Pulau Pinang, Malaysia. \\ ${ }^{2}$ Department of Materials, Imperial College London, Prince Consort Road, \\ London SW7 2AZ, U.K. \\ E-mail: chhussein@eng.usm.my
}

(Submitted: July 15, 2011 ; Revised: October 24, 2011 ; Accepted: November 1, 2011)

\begin{abstract}
Calcium phosphate (CaP) nanoshells were prepared using negatively charged liposomes (1,2-dioleoyl-sn-glycero-3-phosphate sodium salt (DOPA)) as a template by base titration synthesis at various concentrations of $\mathrm{NaOH}$ and calcium ions. The elemental composition, morphology, particle size, particle size distribution and zeta potential of the products were determined via various characterisation techniques, such as energy-dispersive X-ray spectrometry (EDX), transmission electron microscopy (TEM), dynamic light scattering (DLS), laser Doppler velocimetry (LDV) and Fourier transform infrared spectroscopy (FTIR). The best results showed that stable spherical CaP nanoshells with a mean particle size of $197.5 \pm 5.8 \mathrm{~nm}$ and a zeta potential of $-34.5 \pm 0.6 \mathrm{mV}$ were successfully formed when $0.100 \mathrm{M}$ sodium hydroxide $(\mathrm{NaOH})$ and $0.100 \mathrm{M}$ calcium ions were used. Moreover, an optimal $\mathrm{pH}$ of 10.52 and a final $\mathrm{Ca} / \mathrm{P}$ molar ratio of 0.97 were achieved under these conditions.

Keywords: Calcium phosphate; Nanoshells; Liposomes; $\mathrm{NaOH}$; calcium ions.
\end{abstract}

\section{INTRODUCTION}

The effort to discover substitutions to repair fatally damaged human bones dates back centuries (Katti, 2004). The common criteria for materials selection for new bone bio-applications are mechanical properties and biocompatibility. Calcium phosphates (CaPs) are attractive bone biomaterials because of their excellent biocompatibility and the non-toxicity of their chemical elements (Kumta et al., 2005). This non-toxicity is attributable to the fact that $\mathrm{CaPs}$, which account for $69 \mathrm{wt} \%$ of bone, are composed of ions (e.g., calcium, sodium) (Hulbert et al., 1972) that are commonly found in the physiological environment (de Groot et al., 1990; Hench, 1998; Kalita et al., 2007). There are many phases of $\mathrm{CaPs}$, which exhibit different crystal structures and $\mathrm{Ca} / \mathrm{P}$ molar ratios (Fernández et al., 1999a; Fernández et al., 1999b; Dorozhkin, 2009). This complexity makes the CaP system unique and also one of the most interesting types of inorganic biomaterials (Kumta et al., 2005).

The performance of $\mathrm{CaPs}$ as biomaterials strongly depends on the chemical composition and physical characteristics, such as structure and particle size (Rey, 1990; Lu et al., 2002). Thus, it is possible to improve both the mechanical and biological performances of $\mathrm{CaPs}$ by controlling their characteristic features through nanotechnology (Best and Bonfield, 1994). Many advances have been made in biomaterials because of the rapid growth of nanotechnology.

$\mathrm{CaP}$ nanoshells are a promising candidate for controlling the particle size and shape of bone biomaterials. Typically, nanoshells are hollow

\footnotetext{
*To whom correspondence should be addressed
} 
spherical structures with a size range of 20 to $200 \mathrm{~nm}$ (Sounderya and Zhang, 2008). The small sizes and spherical shapes of nanoshells make them ideal for injection into the body (Ishikawa, 2003; Dorozhkin, 2008; Sounderya and Zhang, 2008). As in nature, the shape of the materials can be controlled by the shape of the template used in their creation (Pileni, 1998). For example, Tjandra et al. (2006) reported the use of a polymeric template to synthesise hollow spherical CaP nanoparticles. However, the removal of this polymeric template is necessary to yield the desired hollow structures. Liposomes, however, are non-toxic, biodegradable and non-immunogenic (Lasic, 1995) and thus are safe to be used in the human body. Based on the studies by Schmidt et al. (2008), 1,2-dioleoyl-sn-glycero-3-phosphate sodium salt (DOPA) liposomes can be used as templates to form CaP nanoshells. The negatively charged head group of DOPA liposomes assists in the localisation of ions around the spherical surface of the nanoshells (Schmidt et al., 2004). A hollow spherical morphology of $\mathrm{CaP}$ nanoshells with an average particle size of $152 \pm 48 \mathrm{~nm}$ was obtained. Meanwhile, the thickness of the $\mathrm{CaP}$ nanoshells depends on the quantity of the base solution (Schmidt et al., 2008). Therefore, the template is not the only controlling factor of the shape of the $\mathrm{CaP}$ nanoshells because some discrepancies arise in the synthesis when using templates (Pileni, 2003). According to Chu and Liu (2006), the structures of cadmium selenide (CdSe) nanospheres synthesised using liposome templates were affected by the concentration of the reaction precursors. Therefore, the various parameters that affect nanoshell size and shape still need to be investigated to produce $\mathrm{CaP}$ nanoshells with better properties than existing $\mathrm{CaP}$ materials. The aim in this paper was to investigate the role of sodium hydroxide $(\mathrm{NaOH})$ and calcium ions on the morphology, composition, particle size and zeta potential of $\mathrm{CaP}$ nanoshells synthesised using a DOPA liposome template. $\mathrm{NaOH}$ increases the $\mathrm{pH}$ and thus controls the supersaturation of the mixture of CaP nanoshells (Schmidt, 2006). Moreover, the addition of $\mathrm{NaOH}$ is known to have a large impact on particle formation (Nishimura et al., 2011). $\mathrm{NaOH}$ is also a bio-friendly selection for a base solution. Other base solutions, such as ammonia, are not suitable for use in biomedical applications and must be removed before the introduction of the shells in vivo (Schmidt, 2006). In addition, the fact that calcium ions are the main element of both CaPs and bone is another key to influencing electrostatic localisation on the DOPA liposome template and the growth of the CaPs on the liposome template (Schmidt et al., 2004).

\section{MATERIALS AND METHODS}

\section{Materials}

Calcium chloride $\left(\mathrm{CaCl}_{2}\right), 85 \%$ phosphoric acid $\left(\mathrm{H}_{3} \mathrm{PO}_{4}\right)$ and sodium hydroxide $(\mathrm{NaOH})$ were commercially obtained from Sigma-Aldrich. DOPA $\left(\mathrm{C}_{39} \mathrm{H}_{72} \mathrm{O}_{8} \mathrm{PNa}\right)$ lipid was supplied by Avanti Polar Lipids. All chemicals were of a commercial analytical grade. Deionised (DI) water was used as solvent.

\section{Synthesis of Calcium Phosphate Nanoshells}

CaP nanoshells were prepared using a base titration method that is a modified version of the method reported by Schmidt et al. (2008). First, the hydrated DOPA solution was stirred at $1000 \mathrm{rpm}$ for $1 \mathrm{~h}$ and sonicated in an ultrasonic bath for $15 \mathrm{~min}$ to reduce the size and improve the size distribution of the DOPA template (Schmidt, 2006). Then, 0.100 $\mathrm{M} \mathrm{CaCl}_{2}$ and $0.100 \mathrm{M} \mathrm{H}_{3} \mathrm{PO}_{4}$ (adjusted to $\mathrm{pH} 7$ with $\mathrm{NaOH}$ ) were added separately to the prepared DOPA liposome template. The mixtures were then stirred at $400 \mathrm{rpm}$ at room temperature. Next, twenty $200 \mu \mathrm{l}$ portions of $\mathrm{NaOH}$ of various concentrations $(0.025 \mathrm{M}, 0.050 \mathrm{M}$, $0.075 \mathrm{M}, 0.100 \mathrm{M}$ or $0.125 \mathrm{M}$ ) were added to the mixtures every 30 min to allow precipitation of $\mathrm{CaPs}$ on the liposome template. The $\mathrm{pH}$ changes during the experiments were measured using a $\mathrm{pH}$ meter (Eutech Instrument Ecoscan pH 5). The mixtures were stirred overnight and then ultra-filtered to separate the unwanted particles using Whatman nucleopore tracketched polycarbonate membranes with a $50 \mathrm{~nm}$ pore size from Fisher Scientific. Finally, before analysis, the mixtures were dried in an oven at $60^{\circ} \mathrm{C}$ for $48 \mathrm{~h}$ to obtain the final product. In this paper, the influences of different concentrations of $\mathrm{NaOH}$ and calcium ions on the final products were investigated. The same procedures were repeated to investigate the effect of calcium ions $(0.050 \mathrm{M}, 0.100 \mathrm{M}, 0.150 \mathrm{M}$ or $0.200 \mathrm{M}$ calcium-ion solutions) with the concentration of $\mathrm{NaOH}$ fixed at $0.100 \mathrm{M}$. The detailed conditions are summarised in Table 1. The investigation focused on $\mathrm{pH}$ changes, the molar ratio of $\mathrm{Ca} / \mathrm{P}$, morphology, particle size, particle size distribution, zeta potential, and chemical bonding to demonstrate the effects of the concentrations of $\mathrm{NaOH}$ and calcium ions on the synthesis of the $\mathrm{CaP}$ nanoshells. 
Table 1: Details of the experimental conditions.

\begin{tabular}{|c|c|c|c|c|}
\hline Mixture/Sample & $\mathbf{N a O H}(\mathbf{M})$ & $\mathbf{C a}^{\mathbf{2 +}} \mathbf{( M )}$ & $\mathbf{P O}_{\mathbf{4}}^{\mathbf{3}} \mathbf{( \mathbf { M } )}$ & $\begin{array}{c}\text { Initial mixture ratio of } \\
\mathbf{C a}^{\mathbf{2 +}} / \mathbf{P O}_{\mathbf{4}}^{\mathbf{3 -}}\end{array}$ \\
\hline C-DOPA-1 & 0.025 & 0.100 & 0.100 & 1.00 \\
C-DOPA-2 & 0.050 & 0.100 & 0.100 & 1.00 \\
C-DOPA-3 & 0.075 & 0.100 & 0.100 & 1.00 \\
C-DOPA-4 & 0.100 & 0.100 & 0.100 & 1.00 \\
C-DOPA-5 & 0.125 & 0.100 & 0.100 & 1.00 \\
C-DOPA-6 & 0.100 & 0.150 & 0.100 & 1.50 \\
C-DOPA-7 & 0.100 & 0.200 & 0.100 & 2.00 \\
C-DOPA-8 & 0.100 & &
\end{tabular}

\section{Characterisation of Calcium Phosphate Nanoshells}

The elemental analysis of the $\mathrm{CaP}$ nanoshells was examined using energy-dispersive X-ray spectrometry (EDX) (Leo Supra 35 VP FESEM). A sample in powder form was spread evenly on top of double-sided carbon tape, which was attached to an aluminium stub. The weight percentages (wt \%) of the elements in the samples were obtained as an average of three values from the EDX results. In addition, the final molar ratios of $\mathrm{Ca} / \mathrm{P}$ were calculated via Eq. (1):

Final molar ratio of $\mathrm{Ca} / \mathrm{P}=\frac{\text { mole fraction of } \mathrm{Ca}}{\text { mole fraction of } \mathrm{P}}=$ $\frac{\left(\frac{\text { weight percentage of } \mathrm{Ca}}{\text { molecular weight of } \mathrm{Ca}}\right)}{\left(\frac{\text { weight percentage of } \mathrm{P}}{\text { molecular weight of } \mathrm{P}}\right)}$

Additionally, the structural morphology analysis of the CaP nanoshells was examined by transmission electron microscopy (TEM) (Philips, Model CM 12); the instrument was operated at $120 \mathrm{keV}$. The samples of $\mathrm{CaP}$ nanoshells were prepared by placing one drop of the sample dispersed in absolute ethanol on a carbon-coated copper grid and then air-drying the sample.

The particle size of the $\mathrm{CaP}$ nanoshells was measured using the dynamic light scattering (DLS) technique. In addition, the particle size distribution was investigated using the polydispersity index. The zeta potentials of the $\mathrm{CaP}$ nanoshells were obtained using the laser Doppler velocimetry (LDV) technique. The DLS and LDV measurements were performed on a Zetasizer Nano ZS (Malvern, UK). The samples of $\mathrm{CaP}$ nanoshells in powder form were dispersed in DI water before being added to the sample cell. Each experiment was repeated in triplicate, and each datum given is the average of 15 runs. All the measurements were performed at room temperature.

Infrared spectra of the samples of $\mathrm{CaP}$ nanoshells were obtained in the transmission mode in the range of $4000 \mathrm{~cm}^{-1}$ to $400 \mathrm{~cm}^{-1}$ using a Fourier transform infrared (FTIR) spectrometer (Perkin-Elmer Spectrum GX) from potassium bromide ( $\mathrm{KBr}$ ) discs containing samples of the $\mathrm{CaP}$ nanoshells. For sample preparation, powder samples were first mixed with $\mathrm{KBr}$ and pressed to form a thin disk for analysis.

\section{RESULTS AND DISCUSSION}

\section{pH Changes and Elemental Analyses}

The initial and final (optimal) $\mathrm{pH}$ values of the mixtures of $\mathrm{CaP}$ nanoshells are reported in Table 2 . Initially, all the mixtures were approximately neutral $(\mathrm{pH} 7)$. The $\mathrm{pH}$ levels of the mixtures increased when $\mathrm{NaOH}$ was added until the maximum $\mathrm{pH}$ (optimal $\mathrm{pH}$ ) was reached. The $\mathrm{pH}$ levels were maintained once the optimal $\mathrm{pH}$ was reached. Their optimal $\mathrm{pH}$ levels, in the range of 9.02 to 11.13 , were obtained when different concentrations of $\mathrm{NaOH}$ were added to the mixtures. $\mathrm{pH}$ levels in the range of 10.40 to 10.52 were obtained when different concentrations of calcium ions were used.

Table 2: Comparison of $\mathrm{pH}$ levels of the mixtures of CaP nanoshells using the DOPA template before and after $\mathrm{NaOH}$ additions.

\begin{tabular}{|c|c|c|}
\hline \multirow{2}{*}{ Mixture } & \multicolumn{2}{|c|}{ pH of mixture } \\
\cline { 2 - 3 } & Initial & Final (Optimal) \\
\hline C-DOPA-1 & 6.80 & 9.02 \\
C-DOPA-2 & 6.81 & 9.70 \\
C-DOPA-3 & 6.80 & 10.07 \\
C-DOPA-4 & 6.85 & 10.52 \\
C-DOPA-5 & 6.85 & 11.13 \\
C-DOPA-6 & 6.80 & 10.52 \\
C-DOPA-7 & 6.81 & 10.45 \\
C-DOPA-8 & 6.80 & 10.40 \\
\hline
\end{tabular}


In addition, Figure 1 (a) and (b) shows the $\mathrm{pH}$ of mixtures of $\mathrm{CaP}$ nanoshells as a function of the number of $\mathrm{NaOH}$ addition for the different concentrations of $\mathrm{NaOH}$ and calcium ions, respectively. Generally, the $\mathrm{pH}$ of the mixtures of $\mathrm{CaP}$ nanoshells varied during the three stages (initiation, localisation and growth) of the synthesis of the $\mathrm{CaP}$ nanoshells. In the initiation stage, the $\mathrm{pH}$ of all mixtures increased rapidly. Then, the $\mathrm{pH}$ increased more gradually from the $3^{\text {rd }}$ to the $9^{\text {th }}$ addition of the $\mathrm{NaOH}$ solutions to reach the localisation stage (see Figure 1 (a)). Calcium and phosphate ions began to localise around the negatively charged liposomes in this localisation stage (Schmidt et al., 2004). This finding was indicated by a significant decrease in the $\mathrm{pH}$ between the $\mathrm{NaOH}$ additions (not shown in Figure 1 (a) and (b)). Finally, the optimal $\mathrm{pH}$ was reached between the $14^{\text {th }}$ and $18^{\text {th }}$ addition of $\mathrm{NaOH}$ for these mixtures; this $\mathrm{pH}$ level was maintained until the $20^{\text {th }}$ $\mathrm{NaOH}$ addition (at the end of the experiment). Hence, the mixture was supersaturated and the growth stage was reached. This last stage is the most important stage in the synthesis of CaP nanoshells because it is during this stage that the growth of CaPs on the liposomes occurs (Schmidt et al., 2006).

The number of $\mathrm{NaOH}$ additions needed to reach the localisation and growth stages for the mixture decreased when the concentrations of $\mathrm{NaOH}$ were increased. For example, when the concentration of calcium ions was maintained for the mixtures C-DOPA-4 (0.100 M NaOH) and C-DOPA-5 (0.125 $\mathrm{M} \mathrm{NaOH})$, the optimal $\mathrm{pH}$ was reached after the $14^{\text {th }}$ addition of $\mathrm{NaOH}$. However, the optimal $\mathrm{pH}$ was only reached after the $18^{\text {th }}$ addition of $\mathrm{NaOH}$ when $0.025 \mathrm{M} \mathrm{NaOH}$ (C-DOPA-1) was used. These results indicate that less time is needed for the growth of $\mathrm{CaPs}$ on the liposome template if a higher concentration of $\mathrm{NaOH}$ is used. This may be because the higher concentration of $\mathrm{NaOH}$ accelerates the growth of calcium and phosphate ions on the liposome template. Thus, the number of $\mathrm{NaOH}$ additions needed and the optimal $\mathrm{pH}$ of the mixtures depend on the concentration of $\mathrm{NaOH}$. The higher the concentration of $\mathrm{NaOH}$ used, the higher the $\mathrm{pH}$ obtained and the lower the number of $\mathrm{NaOH}$ additions required.

For different concentrations of calcium ions, the $\mathrm{pH}$ level initially increases rapidly (initiation stage) and then gradually increases (localisation stage) from the $4^{\text {th }}$ to the $5^{\text {th }} \mathrm{NaOH}$ addition. Finally, at the growth stage, the optimal $\mathrm{pH}$ was reached between the $13^{\text {th }}$ and $15^{\text {th }} \mathrm{NaOH}$ addition for these mixtures and was maintained until the $20^{\text {th }} \mathrm{NaOH}$ addition (see Figure 1 (b)). Unlike the mixtures with different concentrations of $\mathrm{NaOH}$, no significant changes in $\mathrm{pH}$ occur when the concentration of calcium ions is increased.

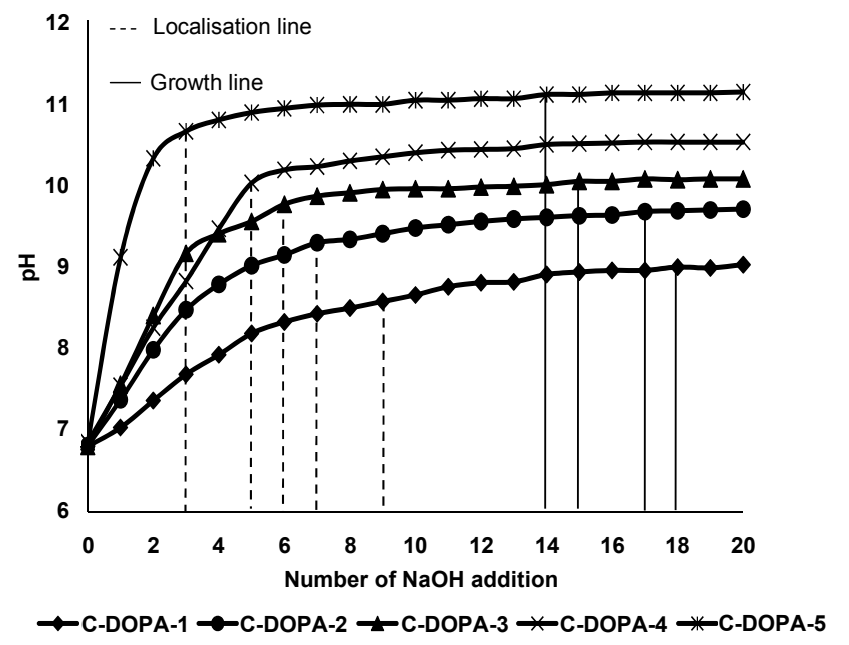

(a)

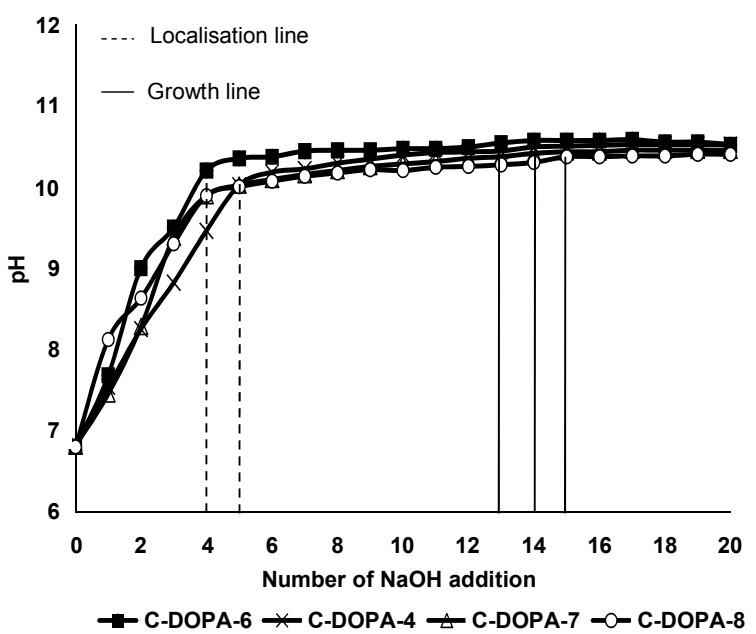

(b)

Figure 1: $\mathrm{pH}$ as a function of the number of $\mathrm{NaOH}$ additions with different: (a) concentrations of $\mathrm{NaOH}$ and (b) concentrations of calcium ions in the synthesis of $\mathrm{CaP}$ nanoshells using the DOPA template. 
Elemental analysis performed on the outer shell of the $\mathrm{CaP}$ nanoshells indicated the wt \% of their elements and allowed the calculation of the final $\mathrm{Ca} / \mathrm{P}$ molar ratio, which is shown in Table 3. Calcium (Ca), phosphorus $(\mathrm{P})$, carbon $(\mathrm{C})$ and oxygen $(\mathrm{O})$ were the major constituents, along with some other minor components, such as sodium $(\mathrm{Na})$ and chloride $(\mathrm{Cl})$. The silicon ( $\mathrm{Si}$ ) content in some of the samples may be attributable to impurities from the glass bottle. In addition, the high wt \% of $\mathrm{C}$ and $\mathrm{O}$ in all the samples originated from the long carbon chains of the DOPA liposome template or were attributable to carbonate ions $\left(\mathrm{CO}_{3}{ }^{2-}\right)$ in the samples. The final $\mathrm{Ca} / \mathrm{P}$ molar ratios were calculated as an average of three values from the EDX results. The final molar ratio of $\mathrm{Ca} / \mathrm{P}$ of sample C-DOPA-4 (0.97) most closely approaches the expected $\mathrm{Ca} / \mathrm{P}$ molar ratio for the $\mathrm{CaP}$ nanoshells (1.00) suggested by Schmidt et al. (2008), which corresponded to either crystalline brushite or amorphous CaPs (ACP) (Markovic et al., 1993; Rodrigues and Lebugle, 1999).
Figure 2 (a) and (b) illustrate the relationships between the final $\mathrm{Ca} / \mathrm{P}$ molar ratios and the final (optimal) $\mathrm{pH}$ levels as functions of the concentrations of $\mathrm{NaOH}$ and calcium ions, respectively. As the concentration of $\mathrm{NaOH}$ was increased to $0.100 \mathrm{M}$ $\mathrm{NaOH}$, the optimal $\mathrm{pH}$ increased; however, the final $\mathrm{Ca} / \mathrm{P}$ molar ratios decreased. The $\mathrm{CaP}$ nanoshells, however, were not usually affected by changes in the final $\mathrm{Ca} / \mathrm{P}$ molar ratios when $\mathrm{NaOH}$ was increased to $0.125 \mathrm{M}$ (C-DOPA-5). From the results obtained, we postulate that sample C-DOPA-5 exhibits properties that differ from those of the other samples. These properties could be related to the highest optimal $\mathrm{pH}$ $(\mathrm{pH}>11)$ obtained in this sample. In addition, the final $\mathrm{Ca} / \mathrm{P}$ ratios of the samples increased as the concentration of calcium ions increased, whereas the optimal $\mathrm{pH}$ for the different calcium ions was maintained between $\mathrm{pH} 10.40$ and 10.55. Under these conditions, the final ratios of the $\mathrm{Ca} / \mathrm{P}$ samples were 0.40 to 1.43 , which are close to the $\mathrm{Ca} / \mathrm{P}$ mixture ratios (0.50 to 2.00$)$.

Table 3: Comparison of the wt $\%$ of the elements and final $\mathrm{Ca} / \mathrm{P}$ molar ratios of $\mathrm{CaP}$ nanoshells using the DOPA template.

\begin{tabular}{|c|c|c|c|c|c|c|c|c|c|c|}
\hline \multirow{2}{*}{ Sample } & \multicolumn{7}{|c|}{ Elements (wt \%) } & \multirow{2}{*}{$\begin{array}{c}\text { Mole } \\
\text { fraction } \\
\text { of } \mathrm{Ca}\end{array}$} & \multirow{2}{*}{$\begin{array}{c}\text { Mole } \\
\text { fraction } \\
\text { of } P\end{array}$} & \multirow{2}{*}{$\begin{array}{l}\text { Final } \\
\mathrm{Ca} / \mathrm{P}\end{array}$} \\
\hline & Ca & $\mathbf{P}$ & C & $\mathbf{O}$ & $\mathbf{N a}$ & $\mathbf{S i}$ & Cl & & & \\
\hline C-DOPA-1 & 26.64 & 8.71 & 10.79 & 19.87 & 22.42 & - & 11.57 & 0.67 & 0.28 & 2.39 \\
\hline C-DOPA-2 & 28.35 & 11.74 & 29.93 & 17.91 & 10.60 & - & 1.48 & 0.71 & 0.38 & 1.87 \\
\hline C-DOPA-3 & 15.97 & 8.21 & 39.46 & 19.36 & 7.89 & 0.21 & 8.90 & 0.40 & 0.26 & 1.54 \\
\hline C-DOPA-4 & 12.64 & 10.36 & 26.76 & 36.90 & 12.23 & - & 1.11 & 0.32 & 0.33 & 0.97 \\
\hline C-DOPA-5 & 9.14 & 3.92 & 22.92 & 35.88 & 26.83 & - & 1.31 & 0.23 & 0.13 & 1.77 \\
\hline C-DOPA-6 & 1.59 & 3.08 & 26.89 & 34.47 & 29.75 & 4.22 & 0.50 & 0.04 & 0.10 & 0.40 \\
\hline C-DOPA-7 & 10.99 & 6.26 & 32.71 & 33.75 & 15.61 & 0.68 & 1.50 & 0.27 & 0.20 & 1.35 \\
\hline C-DOPA-8 & 11.99 & 6.50 & 24.41 & 24.70 & 24.54 & 7.86 & 2.00 & 0.30 & 0.21 & 1.43 \\
\hline
\end{tabular}

Note: The wt $\%$ of elements were obtained as the average from three values in EDX results and the final molar ratios of Ca/P were calculated using Eq. (1)

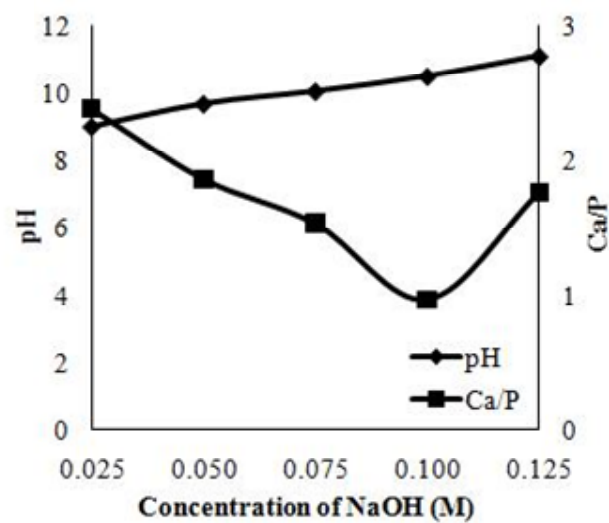

(a)

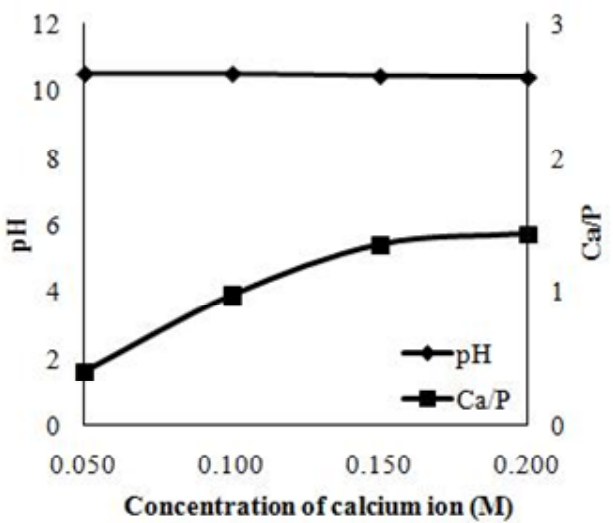

(b)

Figure 2: The relationship between $\mathrm{Ca} / \mathrm{P}$ molar ratio and $\mathrm{pH}$ levels of $\mathrm{CaP}$ nanoshells using the DOPA template as a function of: (a) concentration of NaOH (Sample: C-DOPA-1 $=0.025 \mathrm{M}$, C-DOPA-2 $=0.050 \mathrm{M}, \mathrm{C}-\mathrm{DOPA}-3=0.075 \mathrm{M}, \mathrm{C}$-DOPA-4 $=0.100 \mathrm{M}, \mathrm{C}-\mathrm{DOPA}-5=0.125 \mathrm{M}$ when the concentration of calcium ions was fixed at $0.100 \mathrm{M})$ ) and (b) concentration of calcium ions (Sample: C-DOPA-6 $=0.050$ M, C-DOPA-4 $=0.100$ M, C-DOPA-7 $=0.150$ M, C-DOPA- $8=0.200 \mathrm{M}$ when the concentration of $\mathrm{NaOH}$ was fixed at $0.100 \mathrm{M}$ ). 
We assume that the sample C-DOPA-4 is the most likely to produce $\mathrm{CaP}$ nanoshells. The difference in the optimal $\mathrm{pH}$ and the final $\mathrm{Ca} / \mathrm{P}$ molar ratio may influence the morphology of the $\mathrm{CaP}$ nanoshells.

\section{Morphological Analysis}

Figure 3 (a-h) presents TEM images of $\mathrm{CaP}$ nanoshells prepared using different concentrations of $\mathrm{NaOH}$ and calcium ions (scale bar $=200 \mathrm{~nm}$ ). Nanosized spherical CaP structures were formed on the DOPA template. The qualitatively best result was exhibited by the sample C-DOPA-4 $(0.100 \mathrm{M}$ $\mathrm{NaOH}$ coupled with $0.100 \mathrm{M}$ calcium ions), in which CaPs successfully grew on the outer layer of the DOPA template. This finding can be observed and proved in Figure 3 (d). Dark-field images confirmed the precipitation of CaPs. However, Figure $3(\mathrm{~d})$ also reveals differences in the thicknesses of the nanoshells. These differences may result from the unbalanced coverage of the CaPs on the DOPA template. Moreover, nanosized spherical particles were observed in samples C-DOPA-1 and C-DOPA-2 (see Figure 3 (a) and (b)), even though the particles had agglomerated or overlapped.

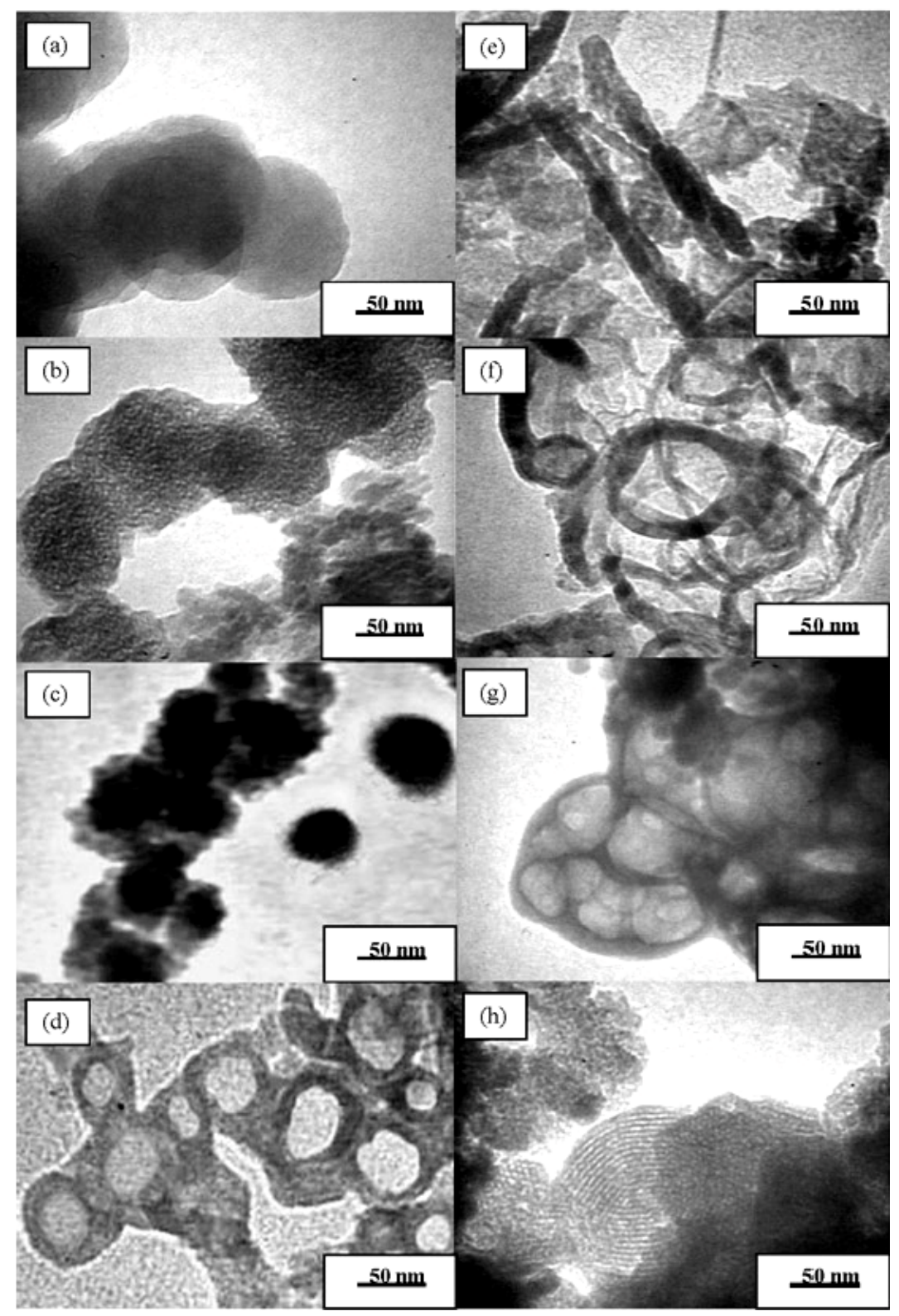

Figure 3: TEM images of $\mathrm{CaP}$ nanoshells prepared using the DOPA template: (a) C-DOPA-1, (b) C-DOPA-2, (c) C-DOPA-3, (d) C-DOPA-4, (e) C-DOPA-5, (f) C-DOPA-6, (g) C-DOPA-7 and (h) C-DOPA-8. 
In Figure 3 (c), the growth of CaPs on the DOPA template as nanosized spherical structures was observed. However, the shell was not observed. This is probably because of a growth unbalance of $\mathrm{CaP}$ nanoparticles on the liposomes, covering the core. The particles almost lost their spherical morphologies and rod or irregular-shaped CaPs were observed when the concentration of $\mathrm{NaOH}$ was increased to $0.125 \mathrm{M}$ or the final $\mathrm{pH}$ of sample C-DOPA-5 reached 11.13. Schmidt (2006) also reported that only hydroxyapatite needles are present and that no visible shells are observed when the $\mathrm{pH}$ is above 11. Schmidt's results indicated that the structures formed by the supersaturated mixtures were vitally influenced by the $\mathrm{pH}$, which is directly controlled by $\mathrm{NaOH}$ addition (Xu et al., 2007). In addition, only a few nanoshells formed in the sample prepared with $0.050 \mathrm{M}$ calcium ions, which could result from fewer calcium ions being provided, because the composition of $\mathrm{Ca}$ and $\mathrm{P}$ were less than 5 wt $\%$ of the sample. Low calcium concentrations are not likely to produce $\mathrm{CaP}$ nanoshells due to the resulting low supersaturation. The nanoshells in sample C-DOPA-7 were in a large cluster, which could result from the shells colliding with the other shells and forming large clusters when an excess of calcium ions $(0.150 \mathrm{M})$ is applied. When the calcium ion concentration is increased to $0.200 \mathrm{M}$, the penetrability of the wall of the template might be increased. In this case, calcium ions were not only adsorbed on the outer surface of the liposome template, but also encapsulated inside the template (Chu and Liu, 2006). Therefore, CaPs grew on the outer surface of template, as well as in the template (see Figure 3 (h)).

This difference in particle morphologies demonstrates that $0.100 \mathrm{M} \mathrm{NaOH}$ coupled with $0.100 \mathrm{M}$ calcium ions results in the best template effect for the growth of CaPs on the DOPA template.

\section{Particles Size, Particle Size Distribution and Zeta Potential Analyses}

Table 4 shows the mean particle size, polydispersity index (particle size distribution) and zeta potential values obtained for the samples of $\mathrm{CaP}$ nanoshells for different concentrations of $\mathrm{NaOH}$ and calcium ions. The mean particle sizes of the $\mathrm{CaP}$ nanoshells were in the range of $173.6 \pm 2.1$ to 427.8 $\pm 77.9 \mathrm{~nm}$. The results show the growth of CaPs on the DOPA template: larger mean particle sizes were observed for the samples of $\mathrm{CaP}$ nanoshells compared with the DOPA template $(64.7 \pm 0.7 \mathrm{~nm})$ (Yeo et al., 2012). The difference in mean particle sizes between sample C-DOPA-4 (best qualitative result) and the DOPA template determined by the DLS method represents the mean nanoshell thickness, which is $132.8 \mathrm{~nm}$.

In addition, the polydispersity index values of the $\mathrm{CaP}$ nanoshells were in the range of $0.260 \pm 0.024$ to $0.527 \pm 0.021$. However, the polydispersity index values exhibited no apparent systematic effect for the samples prepared with different concentrations of $\mathrm{NaOH}$. Nevertheless, the highest polydispersity index value (highest particle size distribution) was observed in sample C-DOPA-5 (highest concentration of $\mathrm{NaOH}$ ), which may be because of its rod-shaped structure. Thus, the DLS method may not be suitable for evaluating the sizes of these non-spherical particles. However, the polydispersity index values increased with increasing concentration of calcium ions, which suggests that the samples became less consistent when the concentration of calcium ions was raised. The samples with lower concentrations of calcium ions exhibited lower polydispersity index values (narrower particle size distribution). The $\mathrm{CaP}$ nanoshells with lower concentrations of calcium ions were monodisperse and uniform compared to the samples that were produced in other conditions.

Table 4: The mean particle size, polydispersity index and zeta potential of CaP nanoshells prepared using the DOPA template.

\begin{tabular}{|c|c|c|c|}
\hline Sample & $\begin{array}{c}\text { Particle size } \\
\text { (nm) }\end{array}$ & $\begin{array}{c}\text { Polydispersity } \\
\text { index }\end{array}$ & $\begin{array}{c}\text { Zeta potential } \\
(\mathbf{m V})\end{array}$ \\
\hline (a) C-DOPA-1 & $427.8 \pm 77.9$ & $0.508 \pm 0.047$ & $-31.7 \pm 1.0$ \\
(b) C-DOPA-2 & $276.5 \pm 4.6$ & $0.404 \pm 0.058$ & $-36.2 \pm 1.4$ \\
(c) C-DOPA-3 & $235.7 \pm 13.6$ & $0.482 \pm 0.099$ & $-37.7 \pm 1.4$ \\
(d) C-DOPA-4 & $197.5 \pm 5.8$ & $0.326 \pm 0.034$ & $-34.5 \pm 0.6$ \\
(e) C-DOPA-5 & $254.7 \pm 3.4$ & $0.527 \pm 0.021$ & $-37.3 \pm 2.9$ \\
(f) C-DOPA-6 & $173.6 \pm 2.1$ & $0.260 \pm 0.024$ & $-56.0 \pm 1.0$ \\
(g) C-DOPA-7 & $248.7 \pm 8.8$ & $0.449 \pm 0.055$ & $-50.6 \pm 0.9$ \\
(h) C-DOPA-8 & $258.3 \pm 73.1$ & $0.456 \pm 0.105$ & $-40.8 \pm 1.8$ \\
\hline
\end{tabular}


In addition, the mean zeta potentials of $\mathrm{CaP}$ nanoshells were in the range of $-31.7 \pm 1.0 \mathrm{mV}$ to $-56.0 \pm 1.0 \mathrm{mV}$. Compared with the bare DOPA liposomes $(-75.3 \pm 2.9 \mathrm{mV}$ ) (Yeo et al., 2012), the magnitudes of all the zeta potentials decreased after the growth of CaPs on the liposomes. The growth of $\mathrm{CaPs}$ on the liposomes clearly affected the zeta potential of the template. Moreover, the liposome (template), which contains phosphatidic acid, possesses an especially strong affinity for calcium ions. Calcium ions exhibit the ability to bind to phosphate groups of the DOPA template, which reduces the relative amount of free, negatively charged phosphate groups (Hautala et al., 2007). Thus, the zeta potential changed from strongly negative to weakly negative. More importantly, $\mathrm{CaP}$ nanoshells prepared with different concentrations of $\mathrm{NaOH}$ and calcium ions and with a zeta potential more negative than $-30 \mathrm{mV}$ are still considered stable.

The relationships between the mean particle size and zeta potential of the $\mathrm{CaP}$ nanoshells as a function of the concentrations of $\mathrm{NaOH}$ and calcium ions are given in Figure 4. As the concentration of $\mathrm{NaOH}$ was increased, the resulting mean particle sizes decreased. This finding may be due to the $\mathrm{CaP}$ nanoshells exhibiting less agglomeration when prepared with higher concentrations of $\mathrm{NaOH}$ (higher $\mathrm{pH}$ value). A higher $\mathrm{pH}$ value reduces the chance of coalescence among particles, increases particle growth rate and results in a better morphology of the particles (Yao et al., 2010). In

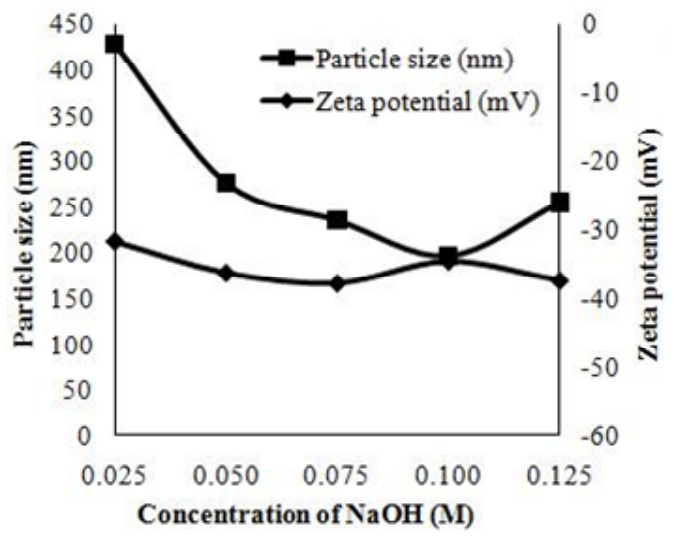

(a) contrast, $\mathrm{CaP}$ nanoshells did not exhibit drastic changes in their zeta potentials as the concentration of $\mathrm{NaOH}$ was increased. However, the zeta potentials are dependent upon particle size (McLaughlin, 1989). A slightly extended positive charge of the calcium ions from the surface of the DOPA template would increase the distance between the slip plane and result in a lower negative zeta potential of the $\mathrm{CaP}$ nanoshells. Therefore, large particles of $\mathrm{CaP}$ nanoshells may exhibit less negative zeta potentials. The mean particle sizes were also found to increase, whereas the mean zeta potential decreased, when the concentration of calcium ions was increased, with the exception of the sample prepared with $0.100 \mathrm{M}$ calcium ions. The negative charge of the DOPA liposome template was suppressed upon increasing of the concentration of calcium ions (Hautala et al., 2007). Thus, the zeta potential changed from strongly negative to weakly negative. However, the most significant change in the zeta potential value was observed in sample C-DOPA-4 (0.100 M NaOH and $0.100 \mathrm{M}$ calcium ions), presumably due to the strong interactions between the calcium ions and the DOPA template, which are uniform in every direction in this sample (Hautala et al., 2007). Thus, the binding of calcium ions is a specificity factor for the change in the zeta potential. In any event, $\mathrm{CaP}$ nanoshells prepared with different concentrations of $\mathrm{NaOH}$ and calcium ions with zeta potentials more negative than $-30 \mathrm{mV}$ are considered stable.

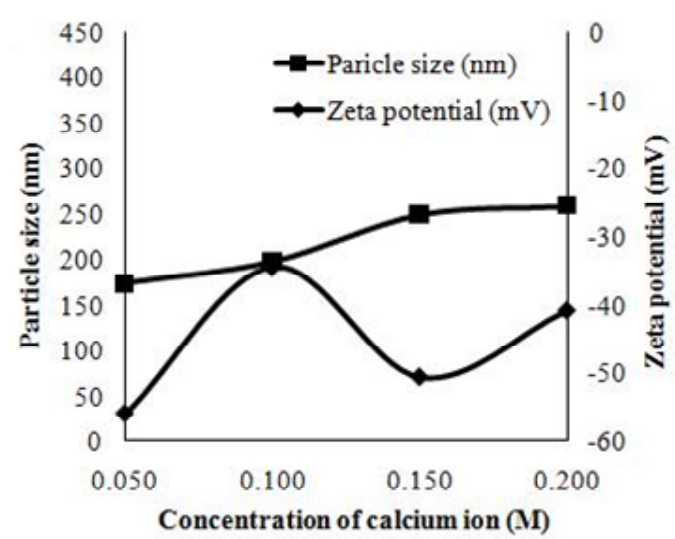

(b)

Figure 4: The relationship between mean particle size and zeta potential of $\mathrm{CaP}$ nanoshells prepared using the DOPA template as a function of: (a) concentration of $\mathrm{NaOH}$ (Sample: C-DOPA-1 $=0.025 \mathrm{M}$, C-DOPA-2 $=0.050 \mathrm{M}$, C-DOPA-3 $=0.075 \mathrm{M}, \mathrm{C}$-DOPA-4 $=0.100 \mathrm{M}, \mathrm{C}-\mathrm{DOPA}-5=0.125 \mathrm{M}$, when the concentration of calcium ions was fixed at $0.100 \mathrm{M}$ ) and (b) concentration of calcium ions (Sample: C-DOPA- $6=0.050 \mathrm{M}, \mathrm{C}-\mathrm{DOPA}-4=0.100 \mathrm{M}, \mathrm{C}-\mathrm{DOPA}-7=0.150 \mathrm{M}, \mathrm{C}-\mathrm{DOPA}-8=0.200 \mathrm{M}$, when the concentration of $\mathrm{NaOH}$ was fixed at $0.100 \mathrm{M}$ ). 
The CaP nanoshells produced using the DOPA template with lower concentrations of calcium ions were more monodisperse than the other samples. The concentration of calcium ions clearly exhibited a greater effect on the zeta potential of the $\mathrm{CaP}$ nanoshells than did the concentration of $\mathrm{NaOH}$.

\section{Chemical Bonding Analysis}

FTIR measurements were used to investigate the chemical bonding in $\mathrm{CaP}$ nanoshells prepared using the DOPA template. Figures 5 (a-e) and 6 (a-d) illustrate the FTIR results for the $\mathrm{CaP}$ nanoshells prepared using different concentrations of $\mathrm{NaOH}$ and calcium ions, respectively. The FTIR spectra of $\mathrm{CaP}$ nanoshells exhibited similar profiles. However, the lowest-intensity FTIR spectrum was obtained for sample C-DOPA-1 and is shown in Figure 5 (a); the weak peaks obtained from this sample may result from its $\mathrm{pH}$, which was the least-optimal final $\mathrm{pH}$ obtained in the experiments.

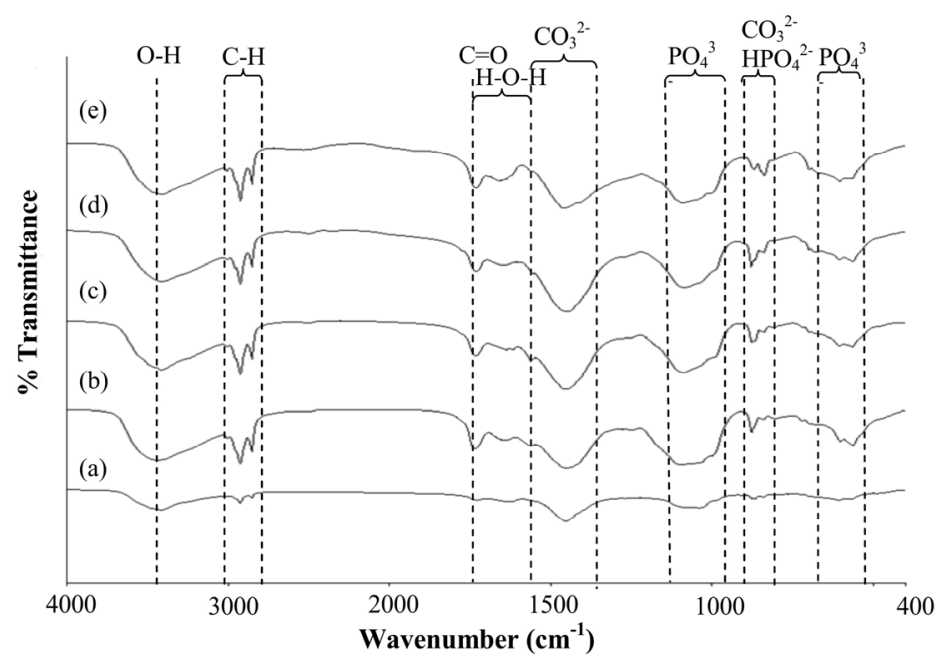

Figure 5: FTIR spectra of $\mathrm{CaP}$ nanoshells prepared using the DOPA template for different concentrations of $\mathrm{NaOH}$ : (a) C-DOPA-1, (b) C-DOPA-2, (c) C-DOPA-3, (d) C-DOPA-4, (e) C-DOPA-5. The dashed lines are included only as a visual guide.

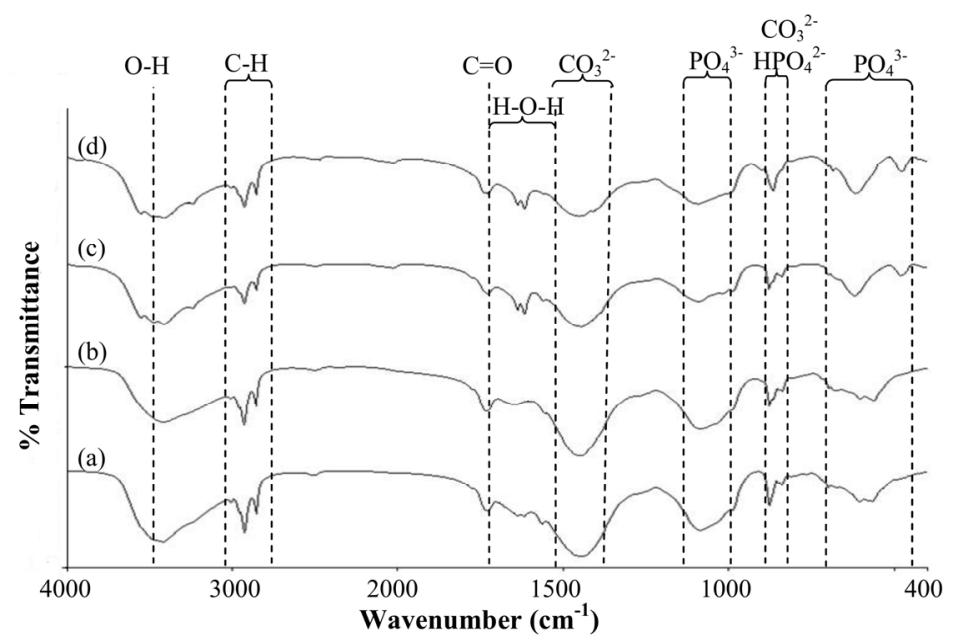

Figure 6: FTIR spectra of $\mathrm{CaP}$ nanoshells prepared using the DOPA template for different concentrations of calcium ions: (a) C-DOPA-6, (b) C-DOPA-4 (same as Figure 5 (d)), (c) C-DOPA-7, and (d) C-DOPA-8. The dashed lines are included only as a visual guide. 
The peaks in the region of $1040 \mathrm{~cm}^{-1}$ and $1090 \mathrm{~cm}^{-1}$ are attributable to phosphate group $\left(\mathrm{PO}_{4}{ }^{3-}\right)$ stretching modes. Interestingly, the peaks attributable to the $\mathrm{PO}_{4}{ }^{3-}$ bending mode split at approximately $605 \mathrm{~cm}^{-1}$ and 565 $\mathrm{cm}^{-1}$ for samples C-DOPA-2, C-DOPA-3, C-DOPA-4, and C-DOPA-6. These split peaks indicate that $\mathrm{CaP}$ nanoshells were partially crystallised (Hirai et al., 2000; Sugawara et al., 2006). These results are in agreement with the EDX results, in which $\mathrm{CaP}$ nanoshells were partially crystalline or amorphous in structure. However, only the peaks at approximately $605 \mathrm{~cm}^{-1}$ appeared for samples C-DOPA-1 and C-DOPA-5. The peaks became wider and shifted to $620 \mathrm{~cm}^{-1}$ and $481 \mathrm{~cm}^{-1}$ for samples C-DOPA-7 and C-DOPA-8. In addition, the greater intensity of the peak at approximately $840 \mathrm{~cm}^{-1}$ (Zhang and Darvell, 2010), with the exception of sample C-DOPA-8 (highest concentration of calcium ions), is attributed to another phosphate group $\left(\mathrm{HPO}_{4}{ }^{2-}\right)$, which indicates calcium deficiency (Elliott, 1994). These results suggest that calcium-deficient hydroxyapatite (CDHA) may not form in samples prepared with $0.200 \mathrm{M}$ calcium ions.

Additionally, the presence of peaks in the region of $1450 \mathrm{~cm}^{-1}$ and near $878 \mathrm{~cm}^{-1}$ in the FTIR spectrum are attributed to carbonate groups $\left(\mathrm{CO}_{3}{ }^{2-}\right)$ (Sugawara et al., 2006; Zyman et al., 2008). The presence of carbonate is due to the substitution of $\mathrm{PO}_{4}{ }^{3-}$ by $\mathrm{CO}_{3}{ }^{2-}$ ions (Sonoda et al., 2002; Kumta et al., 2005). Based on the results of LeGeros (1991), HA contains $\mathrm{CO}_{3}{ }^{2-}$ and is well known to show better bioactivity than stoichiometric HA because of its parallel to the composition of biological apatite in natural bone. Thus, the $\mathrm{CaP}$ nanoshells obtained in this paper are expected to reveal good biocompatibility.

Carbonyl group $(\mathrm{C}=\mathrm{O})$ stretching vibrations appeared at approximately $1730 \mathrm{~cm}^{-1}$ (Dluhy et al., 1983; Zhang et al., 2003). The $\mathrm{C}-\mathrm{H}$ bonds of the hydrocarbon chains (Dluhy et al., 1983) also produced peaks in the region of $2854 \mathrm{~cm}^{-1}$ and $2926 \mathrm{~cm}^{-1}$; this finding also reflects the use of the DOPA template (Schmidt et al., 2006). However, the peaks did not shift when the concentrations of $\mathrm{NaOH}$ and calcium ions were changed.

Moreover, the strongest peaks, attributed to the stretching of hydroxyl groups $(\mathrm{O}-\mathrm{H})$, were observed at approximately $3410 \mathrm{~cm}^{-1}$ (Kumta et al., 2005). The hydroxyl groups in the samples prepared using liposomes also contribute to the negatively charged polar headgroups $(\mathrm{O}-\mathrm{H})$ of the liposomes. In addition, the peaks at $3550 \mathrm{~cm}^{-1}$ for samples prepared with higher concentrations of calcium ions (C-DOPA-7 and C-DOPA-8) were derived from other stretching modes of $\mathrm{O}-\mathrm{H}$ in $\mathrm{CaP}$ nanoshells. On the contrary, for samples prepared with lower concentrations of calcium ions (C-DOPA-6 and C-DOPA-4), the peaks at $3550 \mathrm{~cm}^{-1}$ were invisible in the spectra, which further implies that both samples were poorly crystallised (Shirkhanzadeh, 1995; Chu and Liu, 2005). The peaks of $\mathrm{H}-\mathrm{O}-\mathrm{H}$ modes attributed to absorbed water were observed at approximately $1650 \mathrm{~cm}^{-1}$ (Chu and Liu, 2005; Kumta et al., 2005).

All the previously discussed FTIR peaks and their positions in the FTIR spectrum confirm the formation of $\mathrm{CaP}$ nanoshells prepared with the DOPA template.

\section{CONCLUSION}

$\mathrm{CaP}$ nanoshells were successfully synthesised by a base titration synthesis using $\mathrm{CaCl}_{2}$ and $\mathrm{H}_{3} \mathrm{PO}_{4}$ as precursors, $\mathrm{NaOH}$ as the base solution and DOPA liposomes as a template. The $\mathrm{NaOH}$ controls the supersaturation of the mixtures. Calcium ions are also important to control the growth of CaPs on the DOPA template. The elemental composition, morphology and particle size properties of the $\mathrm{CaP}$ nanoshells were influenced by the concentration of $\mathrm{NaOH}$. The elemental composition, morphology, particle size and zeta potential were also affected by the concentration of calcium ions. As a result of our experiments, we concluded that the best result was obtained for the spherical CaP nanoshells with a mean particle size of $197.5 \pm 5.8 \mathrm{~nm}$ and a final $\mathrm{Ca} / \mathrm{P}$ molar ratio of 0.97 that were formed in sample C-DOPA-4 using the DOPA template with $0.100 \mathrm{M} \mathrm{NaOH}$ and $0.100 \mathrm{M}$ calcium ions at final $\mathrm{pH}$ of 10.52 . The hollowness of the shell structure was verified using TEM. The final $\mathrm{Ca} / \mathrm{P}$ molar ratio of the $\mathrm{CaP}$ nanoshells in this case also approached the expected $\mathrm{Ca} / \mathrm{P}$ molar ratio of 1.00 . All of the $\mathrm{CaP}$ nanoshells with a zeta potential more negative than $-30 \mathrm{mV}$ are considered stable. The main functional groups observed in the $\mathrm{CaP}$ nanoshells were $\mathrm{PO}_{4}{ }^{3-}, \mathrm{HPO}_{4}{ }^{2-}, \mathrm{CO}_{3}{ }^{2-}, \mathrm{C}=\mathrm{O}, \mathrm{C}-\mathrm{H}, \mathrm{O}-\mathrm{H}$ and $\mathrm{H}-\mathrm{O}-\mathrm{H}$. All the observed peaks and their positions in the FTIR spectrum confirm the formation of $\mathrm{CaP}$ nanoshells using the DOPA template. In summary, concerning the properties of the nanoshells produced over the DOPA template, $0.100 \mathrm{M} \mathrm{NaOH}$ coupled with $0.100 \mathrm{M}$ calcium ions is the most suitable condition for the growth of $\mathrm{CaP}$ nanoshells.

\section{ACKNOWLEDGEMENTS}

The financial support provided by the British Council (UK Prime Minister's Initiative for International Education (PMI2) Connect scheme), 
Universiti Sains Malaysia (Research University (RU) grant (Account No. 814143) and Research University Postgraduate Research Grant Scheme (USM-RU-PRGS)) are gratefully acknowledged. Chiew Hwee Yeo also acknowledges a USM Fellowship for the support of her studies. The authors acknowledge helpful discussions with Prof. A. R. Boccaccini (University of Erlangen-Nuremberg, Germany).

\section{REFERENCES}

Best, S. \& Bonfield, W., Processing behaviour of hydroxyapatite powders with contrasting morphology. Journal of Materials Science: Materials in Medicine, 5, 516-521 (1994).

Chu, M. \& Liu, G., Synthesis of liposomestemplated CdSe hollow and solid nanospheres. Materials Letters, 60, No. 1, 11-14 (2006).

Chu, M. Q. \& Liu, G. J., Preparation and characterization of hydroxyapatite/liposome core-shell nanocomposites. Nanotechnology, 16, 1208-1212 (2005).

De Groot, K., Klein, C. P. A. T., Wolke, J. G. C. \& De Bliek-Hogervorst, J. M. A., Chemistry of calcium phosphate bioceramics. IN Boca Raton, F. L. (Ed.) CRC handbook of bioactive ceramics, calcium phosphate and hydroxyapatite ceramics. CRC Press (1990).

Dluhy, R., Cameron, D. G., Mantsch, H. H. \& Mendelsohn, R., Fourier transform infrared spectroscopic studies of the effect of calcium ions on phosphatidylserine. Biochemistry, 22, No. 26, 6318-6325 (1983).

Dorozhkin, S. V., Calcium orthophosphate cements for biomedical application. Journal of Materials Science, 43, 3028-3057 (2008).

Dorozhkin, S. V., Calcium orthophosphates in nature, biology and medicine. Materials, 2, 399498 (2009).

Elliott, J. C. Structure and chemistry of the apatites and other calcium phosphates. Amsterdam: Elsevier Science B.V. (1994).

Fernández, E., Gil, F. J., Ginebra, M. P., Driessens, F. C. M., Planell, J. A. \& Best, S. M., Calcium phosphate bone cements for clinical applications. Part I: Solution chemistry. Journal of Materials Science: Materials in Medicine, 10, No. 3, 169176 (1999a).

Fernández, E., Gil, F. J., Ginebra, M. P., Driessens, F. C. M., Planell, J. A. \& Best, S. M., Calcium phosphate bone cements for clinical applications. Part II: Precipitate formation during setting reactions. Journal of Materials Science: Materials in Medicine, 10, No. 3, 177-183 (1999b).

Hautala, J. T., Riekkola, M.-L. \& Wiedmer, S. K., Anionic phospholipid coatings in capillary electrochromatography: Binding of $\mathrm{Ca}^{2+}$ to phospholipid phosphate group. Journal of Chromatography A, 1150 , No. 1-2, 339-347 (2007).

Hench, L. L., Bioceramics. Journal of the American Ceramic Society, 81, No. 7, 1705-1728 (1998).

Hirai, T., Hodono, M. \& Komasawa, I., The preparation of spherical calcium phosphate fine particles using an emulsion liquid membrane system. Langmuir, 16, No. 3, 955-960 (2000).

Hulbert, S. F., Klawitter, J. J. \& Bowman, L. S., History of ceramic orthopedic implants. Materials Research Bulletin, 7, No. 11, 1239-1246 (1972).

Ishikawa, K., Effects of spherical tetracalcium phosphate on injectability and basic properties of apatitic cement. Key Engineering Materials, 240242, 369-372 (2003).

Kalita, S. J., Bhardwaj, A. \& Bhatt, H. A., Nanocrystalline calcium phosphate ceramics in biomedical engineering. Materials Science and Engineering: C., 27, 441-449 (2007).

Katti, K. S., Biomaterials in total joint replacement. Colloids and Surfaces B: Biointerfaces, 39, No. 3, 133-142 (2004).

Kumta, P. N., Sfeir, C., Lee, D. H., Olton, D. \& Choi, D., Nanostructured calcium phosphates for biomedical applications: novel synthesis and characterization. Acta Biomaterialia, 1, No. 1, 6583 (2005).

Lasic, D. D., Applications of liposomes. IN Lipowsky, R., Sackmann, E. (Ed.) Handbook of Biological Physics (1995).

Legeros, R. Z., Calcium phosphates in oral biology and medicine. IN Myers, H., E (Ed.) Monographs in Oral Sciences. Karger: Basel (1991).

Lu, J., Descamps, M., Dejou, J., Koubi, G., Hardouin, P., Lemaitre, J. \& Proust, J.-P., The biodegradation mechanism of calcium phosphate biomaterials in bone. Journal of Biomedical Materials Research, 63, 408-412 (2002).

Markovic, M., Fowler, B. O. \& Brown, W. E., Octacalcium phosphate carboxylates. 2. Characterization and structural considerations. Chemistry of Materials, 5, No. 10, 1406-1416 (1993).

Mclaughlin, S., The electrostatic properties of membranes. Annual Review of Biophysics and Biophysical Chemistry, 18, No. 1, 113-136 (1989).

Nishimura, S., Mott, D., Takagaki, A., Maenosono, S. \& Ebitani, K., Role of base in the formation of 
silver nanoparticles synthesized using sodium acrylate as a dual reducing and encapsulating agent. Physical Chemistry Chemical Physics, 13, No. 20, 9335-9343 (2011).

Pileni, M. P., Fabrication and properties of nanosized material made by using colloidal assemblies as templates. Crystal Research and Technology, 33, No. 7-8, 1155-1186 (1998).

Pileni, M. P., The role of soft colloidal templates in controlling the size and shape of inorganic nanocrystals. Nature Materials, 2, 145-150 (2003).

Rey, C., Calcium phosphate biomaterials and bone mineral. Differences in composition, structures and properties. Biomaterials, 11, 13-15 (1990).

Rodrigues, A. \& Lebugle, A., Behavior in wet atmosphere of an amorphous calcium phosphate with an atomic $\mathrm{Ca} / \mathrm{P}$ ratio of 1.33 . Journal of Solid State Chemistry, 148, No. 2, 308-315 (1999).

Schmidt, H. T., Calcium phosphate based nanoshells for use in biomedical applications. University of Notre Dame, Indiana (2006).

Schmidt, H. T., Gray, B. L., Wingert, P. A. \& Ostafin, A. E., Assembly of aqueous-cored calcium phosphate nanoparticles for drug delivery. Chemistry of Materials, 16, No. 24, 4942-4947 (2004).

Schmidt, H. T., Kroczynski, M., Maddox, J., Chen, Y., Josephs, R. \& Ostafin, A. E., Antibodyconjugated soybean oil-filled calcium phosphate nanoshells for targetted delivery of hydrophobic molecules. Journal of Microencapsulation 23, No. 7, 769-781 (2006).

Schmidt, S. M., Moran, K. A., Kent, A. M. T., Slosar, J. L., Webber, M. J., Mccready, M. J., Deering, C., Veranth, J. M. \& Ostafin, A., Uptake of calcium phosphate nanoshells by osteoblasts and their effect on growth and differentiation. Journal of Biomedical Materials Research Part A, 87A, No. 2, 418-428 (2008).

Shirkhanzadeh, M., Calcium phosphate coatings prepared by electrocrystallization from aqueous electrolytes. Journal of Materials Science: Materials in Medicine, 6, No. 2, 90-93 (1995).

Sonoda, K., Furuzono, T., Walsh, D., Sato, K. \&
Tanaka, J., Influence of emulsion on crystal growth of hydroxyapatite. Solid State Ionics, 151, No. 1-4, 321-327 (2002).

Sounderya, N. \& Zhang, Y., Use of core/shell structured nanoparticles for biomedical applications. Recent Patents on Biomedical Engineering, 1, 34-42 (2008).

Sugawara, A., Yamane, S. \& Akiyoshi, K., Nanogeltemplated mineralization: Polymer-calcium phosphate hybrid nanomaterials. Macromolecular Rapid Communications, 27, No. 6, 441-446 (2006).

Tjandra, W., Ravi, P., Yao, J. \& Tam, K. C., Synthesis of hollow spherical calcium phosphate nanoparticles using polymeric nanotemplates. Nanotechnology, 17, No. 24, 5988-5994 (2006).

$\mathrm{Xu}$, Q., Tanaka, Y. \& Czernuszka, J. T., Encapsulation and release of a hydrophobic drug from hydroxyapatite coated liposomes. Biomaterials, 28, No. 16, 2687-2694 (2007).

Yao, Z., Chen, H. J., Qin, Y. X. \& Cao, K., Effect of $\mathrm{pH}$ value on the aqueous precipitation copolymerization of acrylonitrile and vinyl acetate. Journal of Applied Polymer Science, 119, No. 3, 1486-1491 (2010).

Yeo, C.-H., Zein, S. H. S., Ahmad, A. L. \& Mcphail, D. S., Comparison of DOPA and DPPA liposome templates for the synthesis of calcium phosphate nanoshells. Ceramics International, 38, 561-570 (2012).

Zhang, H. \& Darvell, B. W., Synthesis and characterization of hydroxyapatite whiskers by hydrothermal homogeneous precipitation using acetamide. Acta Biomaterialia, 6, No. 8, 32163222 (2010).

Zhang, W., Huang, Z. L., Liao, S. S. \& Cui, F. Z., Nucleation sites of calcium phosphate crystals during collagen mineralization. Journal of the American Ceramic Society, 86, No. 6, 1052-1054 (2003).

Zyman, Z. Z., Tkachenko, M. V. \& Polevodin, D. V., Preparation and characterization of biphasic calcium phosphate ceramics of desired composition. Journal of Materials Science: Materials in Medicine, 19, 2819-2825 (2008). 